\title{
The influence of blood transfusion on survival in operated non-small cell lung cancer patients
}

Witold Rzyman, MD, PhD ${ }^{a}$

Rafal Dziadziuszko, MD, $\mathrm{PhD}^{\mathrm{b}}$

Jan Skokowski, MD, PhD

Radoslaw Wilimski, MD

Artur Raiter, MD

Amelia Szymanowska, $\mathrm{MD}^{\mathrm{c}}$

Jacek Jassem, MD, PhD ${ }^{\mathrm{b}}$
From the Departments of Thoracic Surgery, ${ }^{\mathrm{a}}$ Oncology and Radiotherapy, ${ }^{\mathrm{b}}$ and Pneumonology, ${ }^{\mathrm{c}}$ Medical University of Gdansk, Gdansk, Poland.

Received for publication Oct 1, 2002; revisions requested Nov 5, 2002; revisions received Nov 28, 2002; accepted for publication Jan 7, 2003.

Address for reprints: Witold Rzyman, MD, $\mathrm{PhD}$, Department of Thoracic Surgery, Medical University of Gdansk, 7 Dêbinki St, 80-211 Gdansk, Poland (E-mail: wrzyman@wp.pl).

J Thorac Cardiovasc Surg 2003;126:755-60

Copyright $\odot 2003$ by The American Association for Thoracic Surgery

$0022-5223 / 2003 \$ 30.00+0$

doi:10.1016/S0022-5223(03)00217-4
Background: It has been postulated that allogeneic transfusions have immunosuppressive effects that can promote tumor growth and metastasis formation. Despite the variety of publications on this controversial topic, the influence of blood transfusion on survival is not yet clearly identified. The impact of autologous blood transfusion on survival has only occasionally been analyzed in cancer patients.

Objective: To determine the effect of perioperative allogeneic and autologous blood transfusions on survival in non-small cell lung cancer patients treated with curative pulmonary resection.

Methods: Of 493 consecutive patients, 185 (37.5\%) received allogeneic blood products and 145 (29.4\%) received autologous blood products, whereas 163 patients (33.1\%) received no blood products. Survival analysis included univariate log-rank test and multivariate Cox regression model.

Results: Three-year survival probabilities in allogeneic, autologous, and nontransfused groups were $40 \%, 48 \%$, and $61 \%$, respectively, and the estimated 5-year survival probabilities were $34 \%, 38 \%$, and $48 \%$, respectively. In the univariate analysis there was a reduced survival in allogeneic versus nontransfused group $(P<$ $.01)$. In the multivariate analysis stage $(P<.01)$, initial hemoglobin level $(P=.01)$ and sedimentation rate $(P=.03)$ remained significant factors, whereas the type of blood transfusion (allogeneic versus autologous) was no longer significant. There was no significant impact of transfusion in the multivariate analysis when patients in stage III or patients who underwent pneumonectomy were excluded.

Conclusion: Neither allogeneic nor autologous blood transfusion has independent, adverse survival impact in non-small cell lung cancer patients treated with radical pulmonary resection.

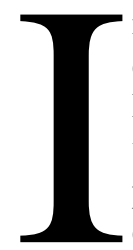

mmunosuppression associated with homologous blood transfusion was first demonstrated in patients undergoing kidney transplantations. ${ }^{1}$ In 1982, Burrows and Tartter ${ }^{2}$ showed that allogeneic blood transfusion is associated with significantly increased risk of tumor recurrence and shorter survival in patients operated for colorectal cancer. Since then, numerous studies addressing experimental and clinical aspects of this phenomenon have been published. The association between perioperative transfusion and increased incidence of bacterial infections has been found in both retrospective and prospective clinical studies. Furthermore, animal studies provided convincing evidence of increased morbidity and mortality related to posttransfusion infections. ${ }^{3-5}$ It has been postulated that allogeneic transfusions promote tumor growth and metastasis 
formation, although immune cells and humoral factors responsible for the immunosuppressive effects of transfusion have not yet been clearly identified. ${ }^{6}$ Most probably a large variety of immunological factors and mechanisms in the blood may be involved in this process.

Due to ethical reasons, the impact of perioperative allogeneic blood transfusion on survival or the risk of relapse in cancer patients has never been assessed in a randomized prospective trial including random allocation to transfusion or no transfusion. Obviously, it would be unethical to transfuse blood without clinical indications or to withhold transfusion in patients who need it. Consequently, the entire knowledge on this issue is based on retrospective studies.

The immunosuppressive effects of allogeneic blood transfusion were analyzed in different types of tumors, most frequently in colorectal cancer. Landers and colleagues ${ }^{7}$ reviewed 36 retrospective studies that analyzed the influence of perioperative blood transfusion on the risk of relapse or survival in patients operated for different tumors. Fifteen studies showed no influence of transfusion and 21 demonstrated its detrimental effect. Of the 6 retrospective studies in lung cancer, 4 showed adverse effect of allogeneic blood transfusion ${ }^{8-11}$ and 2 did not. ${ }^{12,13}$

The current knowledge on the effects of autologous blood transfusion is relatively scarce. Transfusion of autologous, predeposited blood was not documented to cause significant immunosuppression in experimental models. ${ }^{14,15}$ Two studies in surgically treated colorectal cancer patients failed to show significant survival impact of allogeneic and autologous blood transfusion, but there was an increased incidence of postoperative infections in transfused patients. ${ }^{6,16,17}$ The prognostic impact of autologous blood transfusion has never been studied in surgically treated non-small cell lung cancer (NSCLC) patients.

This retrospective analysis assessed the prognostic relevance of allogeneic and autologous blood transfusions in a large series of NSCLC patients treated with curative pulmonary resection.

\section{Materials and Methods \\ Patients}

A total of 493 of 538 consecutive patients who underwent thoracotomy for NSCLC between December 1993 and February 1997 were included into the study (Table 1). Nineteen patients were excluded due to incomplete data and 26 due to inoperability or incomplete resection. The following data were recorded: age, sex, amount and type of transfused blood, hemoglobin level, sedimentation rate, histological type of cancer, tumor location, type of resection, and pathological staging according to the last revision (1997) of International Union Against Cancer/American Joint Commission lung cancer staging system.

Three hundred twenty-five patients $(65.9 \%)$ predeposited their own blood preoperatively. Patients were divided into 3 groups depending on the transfusion history: only autologous transfusion, allogeneic transfusion (with or without autologous transfusion), and no transfusion. Patients who received both autologous and allogeneic blood transfusion were considered as allogeneic group.

\section{Methods}

Patients who donated their own blood were scheduled to deposit 2 units of blood ( $450 \mathrm{~mL} / \mathrm{unit}$ ) between 6 and 3 days before surgery. The level of hemoglobin concentration above $12 \mathrm{~g} / \mathrm{dL}$ was considered a minimal value for predeposition, whereas hemoglobin level below $8 \mathrm{~g} / \mathrm{dL}$ accompanied by the evidence of inadequate tissue oxygenation (tachycardia, low blood pressure, etc) was the indication for perioperative autologous or allogeneic blood transfusion. In this analysis, only blood transfusions during hospitalization were considered. No patient received blood transfusion preoperatively. All patients received prophylactic antibiotics and anticoagulative agents. Transfusion material included whole blood or packed red blood cells. All autologous blood that was not retransfused to the donor was discarded. The operations were performed under general anesthesia with the same routine rules for all the patients. The surgical approach was standardized: the anatomical lung resection was performed first, followed by systemic complete dissection of hilar and mediastinal lymph nodes. Operations were performed by 8 surgeons: 4 specialized thoracic surgeons and 4 surgeons training to be thoracic surgeons due to the educational character of the department. Pathological assessment was done in 1 laboratory, and then pathological lung cancer staging status was established. In principle, adjuvant irradiation or chemotherapy was not administered; however, a few patients received radio- or chemotherapy according to individual decisions of the treating physicians. After the discharge from the hospital, all patients were followed up in the outpatient clinic every 3 months for 2 years and twice a year later on. Follow-up ranged from 26 to 73 months (median 46 months). Death certificates from provincial registry were used to confirm the death.

\section{Statistical Analysis}

Survival probability and its $95 \%$ confidence interval (CI) were computed using the Kaplan and Meier method, with the date of the operation set as zero time. Postoperative 30-day deaths were included in the survival analysis. The log-rank statistic was used for the univariate statistical comparisons of survival curves. The Cox proportional hazard model was used to calculate hazard ratio and its $95 \%$ CI for particular variables in univariate and multivariate model. In the multivariate model, backward-stepwise regression was used and insignificant variables were removed from the model based on the Wald's test. Additionally, a forward-stepwise model was employed to assure that the construction of the model would not influence the results.

\section{Results}

Of the 493 patients eligible for inclusion in to the study, 330 $(66.9 \%)$ received blood transfusions. One hundred fortyfive patients $(29.4 \%)$ received autologous blood transfusions, 185 patients $(37.5 \%)$ received allogeneic blood transfusions with (96 patients; 19.5\%) or without (89 patients; $18.0 \%$ ) autologous blood transfusions, and 163 patients $(33.1 \%)$ did not receive transfusions. Of the transfused patients, $122(40.0 \%)$ received 1 unit of blood, $87(20.3 \%)$ 
TABLE 1. Patient and treatment characteristics

\begin{tabular}{|c|c|c|c|c|}
\hline Variable & All patients, $n=493$ & No transfusion, $n=163$ & Autologous transfusion, $n=145$ & Allogeneic transfusion, $n=185$ \\
\hline \multicolumn{5}{|l|}{ Sex } \\
\hline Male & $393(80 \%)$ & $125(77 \%)$ & $113(78 \%)$ & $155(84 \%)$ \\
\hline Female & $100(20 \%)$ & $38(23 \%)$ & $32(22 \%)$ & $30(16 \%)$ \\
\hline \multicolumn{5}{|l|}{ Age } \\
\hline Range & $34-78$ & $34-77$ & $40-77$ & $37-78$ \\
\hline Mean & 59.7 & 60.3 & 59.4 & 59.5 \\
\hline \multicolumn{5}{|l|}{ Hemoglobin level } \\
\hline$\leq 12 \mathrm{~g} / \mathrm{dL}$ & $82(17 \%)$ & $19(12 \%)$ & $17(12 \%)$ & $46(25 \%)$ \\
\hline$>12 \mathrm{~g} / \mathrm{dL}$ & $411(83 \%)$ & $144(88 \%)$ & $128(88 \%)$ & $139(75 \%)$ \\
\hline \multicolumn{5}{|l|}{ Sedimentation rate } \\
\hline$\leq 40$ & $212(48 \%)$ & $85(60 \%)$ & $68(51 \%)$ & $59(36 \%)$ \\
\hline$>40$ & $226(52 \%)$ & $57(40 \%)$ & $64(49 \%)$ & $105(64 \%)$ \\
\hline \multicolumn{5}{|l|}{ Pathology } \\
\hline SCC & $316(64 \%)$ & $108(66 \%)$ & $95(65 \%)$ & $113(61 \%)$ \\
\hline$A C$ & $127(26 \%)$ & $43(26 \%)$ & $33(23 \%)$ & $51(28 \%)$ \\
\hline LCC & $42(8.5 \%)$ & $9(5.5 \%)$ & $14(9.6 \%)$ & $19(10 \%)$ \\
\hline Other & $8(1.6 \%)$ & $3(1.8 \%)$ & $3(2.1 \%)$ & $2(1.1 \%)$ \\
\hline \multicolumn{5}{|l|}{ Tumor localization } \\
\hline Left lung & $219(44 \%)$ & $75(46 \%)$ & $70(48 \%)$ & $74(40 \%)$ \\
\hline Right lung & $274(56 \%)$ & $88(54 \%)$ & $75(52 \%)$ & $111(60 \%)$ \\
\hline \multicolumn{5}{|c|}{ Pathological tumer stage } \\
\hline IA & $24(4.9 \%)$ & $13(8 \%)$ & $3(2.1 \%)$ & $8(4.3 \%)$ \\
\hline IB & $184(37.3 \%)$ & $72(44.2 \%)$ & $58(40 \%)$ & $54(29.2 \%)$ \\
\hline IIA & $3(0.6 \%)$ & $1(0.6 \%)$ & 0 & $2(1.1 \%)$ \\
\hline IIB & $103(20.9 \%)$ & $32(19.6 \%)$ & $32(22 \%)$ & $39(21.1 \%)$ \\
\hline IIIA & $130(26.4 \%)$ & $32(19.6 \%)$ & $39(26.9 \%)$ & $59(31.9 \%)$ \\
\hline IIIB & $38(7.7 \%)$ & $9(5.5 \%)$ & $8(5.5 \%)$ & $21(11.4 \%)$ \\
\hline IV & $11(2.2 \%)$ & $4(2.5 \%)$ & $5(3.5 \%)$ & $2(1.1 \%)$ \\
\hline \multicolumn{5}{|l|}{ Type of surgery } \\
\hline Wedge resection & $6(1.2 \%)$ & $5(3.1 \%)$ & 0 & $1(0.5 \%)$ \\
\hline Segmentectomy & $12(2.4 \%)$ & $8(4.9 \%)$ & $1(0.7 \%)$ & $3(1.6 \%)$ \\
\hline Lobectomy & $283(57.4 \%)$ & $97(59.5 \%)$ & $87(60 \%)$ & $99(53.5 \%)$ \\
\hline Bilobectomy & $24(4.9 \%)$ & $11(6.7 \%)$ & $3(2.1 \%)$ & $10(5.4 \%)$ \\
\hline Pneumonectomy & $168(34.1 \%)$ & $42(25.8 \%)$ & $54(37.2 \%)$ & $72(38.9 \%)$ \\
\hline \multicolumn{5}{|l|}{ Additional treatment } \\
\hline Radiotherapy & $37(7.5 \%)$ & $9(5.5 \%)$ & $11(7.6 \%)$ & $17(9.2 \%)$ \\
\hline Chemotherapy & $20(4.1 \%)$ & $4(2.5 \%)$ & $6(4.1 \%)$ & $10(5.4 \%)$ \\
\hline
\end{tabular}

SCC, Squamous cell carcinoma; $A C$, adenocarcinoma; $L C C$, large cell carcinoma.

received 2 units, and 121 patients $(39.7 \%)$ received 3 or more units of blood. Of the 325 patients who predeposited their blood preoperatively, $253(77.8 \%)$ were transfused including 145 patients $(44.6 \%)$ who received autologous blood only and 108 (33.2\%) who received autologous and allogeneic blood. Twenty-three patients $(4.7 \%)$ died within 30 days after surgical treatment, and 176 patients $(35.7 \%)$ had postoperative complications. In these 2 groups, 15 $(65.2 \%)$ and 119 patients (67.6\%), respectively, received blood transfusion.

Most of the analyzed variables, except for sedimentation rate, hemoglobin level, and lung cancer staging status, were similarly distributed in the analyzed groups (Table 1).

Median survival for autologous, allogeneic, and nontransfused groups were $2.9,1.7$, and 4.4 years, respectively (Figure 1). Three-year survival probabilities $( \pm 95 \mathrm{CI})$ were
$48 \%(39-56 \%), 40 \%(33-47 \%)$, and 61\% (53-68\%), respectively, and 5-year survival probabilities were 38\% (29$48 \%$ ), 34\% (27-41\%), and 48\% (37-59\%), respectively.

In the univariate analysis considering history of transfusion as single variable, there was a significantly reduced survival in nontransfused versus allogeneic group $(P<.01$; Table 2). There was a trend toward reduced survival in autologous versus nontransfused group and in allogeneic versus autologous group $(P=.08$ and .11 , respectively; Figure 1). Other factors found to be associated with survival in univariate analysis included initial hemoglobin level, sedimentation rate, and tumor stage.

In multivariate analysis using the Cox proportional hazard model with the adjustment for initial hemoglobin level, sedimentation rate, and tumor stage, adverse impact of allogeneic blood transfusion was lost (Table 2). 


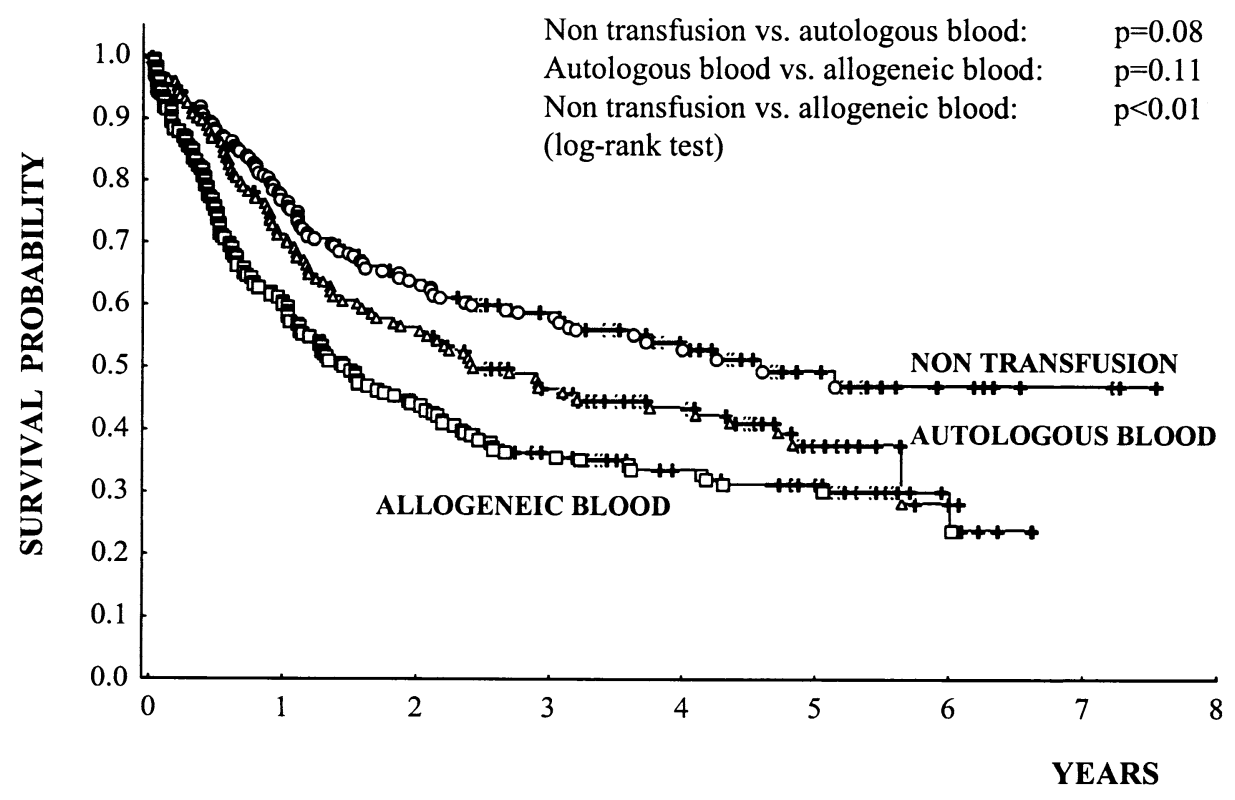

Figure 1. Probability of survival according to history of transfusion.

There was a significant difference in survival between the entire group of transfused patients versus nontransfused patients $(P=.017)$ in univariate analysis, but during the backward-stepwise regression in Cox model this variable was excluded as nonsignificant. The same results were obtained with forward-stepwise model, indicating that the type of the model does not influence the results.

The resections in NSCLC patients with stage IIIA and IIIB tumors are often considered as palliative management. Since the possible detrimental effect of blood transfusion is of particular importance for patients with early-stage disease, we have repeated the analysis on 314 patients with stage I and II tumors. In the univariate analysis in this subset there was no 5-year survival difference between the nontransfused and autologous group $(P=.20)$, nontransfused and allogeneic group $(P=.70)$, or autologous and allogeneic group $(P=.09)$.

Finally, to eliminate the extent of resection as a cofactor, we excluded 168 patients who underwent pneumonectomy. This analysis, restricted to 325 patients who had either lobectomy or sublobar resection (wedge resections were excluded), showed significant survival difference in univariate analysis between nontransfused and allogeneic groups $(P<.01)$. There was, however, no significant difference between nontransfused and autologous $(P=.65)$ and autologous and allogeneic groups $(P=.06)$. In the multivariate analysis including these 325 patients, only hemoglobin level and stage of disease remained significant (both $P<$ .01 ), whereas prognostic impact of allogeneic transfusion was lost.

\section{Discussion}

The results of retrospective studies addressing the influence of allogeneic blood transfusion in cancer patients on relapse-free or overall survival are contradictory. ${ }^{5,7}$ The metaanalysis of 8 trials failed to confirm the hypothesis that perioperative blood transfusion is associated with increased risk of postoperative infection, cancer recurrence, or mortality in patients undergoing potentially curative surgery. ${ }^{18}$ Although the power of this meta-analysis was too low to detect small differences, it showed that the magnitude of any adverse effects on survival or cancer recurrence from allogeneic transfusion, if any, is below $20 \%$.

The data on the prognostic impact of allogeneic blood transfusion in patients operated for NSCLC are limited and provide contradictory results (Table 3 ). So far, there have been only 2 published studies including more than 300 patients. ${ }^{11,12}$ Often, a limited number of known prognostic factors have been included in the multivariate analysis. Furthermore, only 3 studies $^{8,10,11}$ included information on initial hemoglobin or hematocrit levels-one of the most important factors determining the need of transfusion and linked to the disease stage and prognosis. In our study, initial hemoglobin level was analyzed and found to predict survival in both univariate and multivariate models. The statistical tests used to analyze the effect of blood transfusion have also varied among particular studies (Table 3). The most reliable test-adjusted hazard ratio and corresponding $95 \%$ confidence interval—has only occasionally been employed. 
TABLE 2. Univariate and multivariate analysis of overall survival

\begin{tabular}{|c|c|c|c|c|c|c|c|}
\hline \multirow[b]{2}{*}{ Variable } & \multirow[b]{2}{*}{$\mathbf{n}$} & \multicolumn{3}{|c|}{ Univariate analysis } & \multicolumn{3}{|c|}{ Multivariate analysis-final model } \\
\hline & & Hazard ratio & 95\% confidence interval & $\boldsymbol{P}$ & Hazard ratio & 95\% confidence interval & $\boldsymbol{P}$ \\
\hline \multicolumn{8}{|l|}{ Sex } \\
\hline Female & 100 & & & & & & \\
\hline Male & 393 & 1.17 & $0.86-1.58$ & .32 & & & NS \\
\hline \multicolumn{8}{|c|}{ Age at diagnosis } \\
\hline$\leq 60$ years & 237 & & & & & & \\
\hline$>60$ years & 256 & 1.10 & $0.87-1.40$ & .41 & & & NS \\
\hline \multicolumn{8}{|l|}{ Weight loss } \\
\hline No & 458 & & & & & & \\
\hline Yes & 35 & 1.24 & $0.79-1.96$ & .35 & & & NS \\
\hline \multicolumn{8}{|c|}{ History of COPD } \\
\hline No & 461 & & & & & & \\
\hline Yes & 32 & 1.08 & $0.68-1.68$ & .78 & & & NS \\
\hline \multicolumn{8}{|c|}{ History of smoking } \\
\hline No & 64 & & & & & & \\
\hline Yes & 429 & 0.78 & $0.55-1.07$ & .12 & & & NS \\
\hline \multicolumn{8}{|c|}{ Hemoglobin level } \\
\hline$\leq 12 \mathrm{~g} / \mathrm{dL}$ & 80 & & & & & & \\
\hline$>12 \mathrm{~g} / \mathrm{dL}$ & 405 & 0.50 & $0.37-0.66$ & $<.01$ & 0.66 & $0.47-0.92$ & .01 \\
\hline \multicolumn{8}{|c|}{ Sedimentation rate } \\
\hline$\leq 40$ & 212 & & & & & & \\
\hline$>40$ & 226 & 1.72 & $1.32-2.23$ & $<.01$ & 1.37 & $1.04-1.81$ & .03 \\
\hline \multicolumn{8}{|c|}{ Blood transfusion } \\
\hline none & 163 & & & & & & \\
\hline autologous & 145 & 1.32 & $0.96-1.81$ & .08 & & & NS \\
\hline allogeneic & 185 & 1.67 & $1.25-2.24$ & $<.01$ & & & NS \\
\hline \multicolumn{8}{|l|}{ Pathology } \\
\hline SCC & 316 & & & & & & \\
\hline$A C$ & 127 & 1.20 & $0.91-1.57$ & .20 & & & NS \\
\hline LCC & 42 & 1.45 & $0.96-2.19$ & .08 & & & NS \\
\hline \multicolumn{8}{|l|}{ Stage } \\
\hline I & 208 & & & & & & \\
\hline II & 105 & 2.01 & $1.45-2.79$ & $<.01$ & 1.77 & $1.25-2.52$ & $<.01$ \\
\hline IIIA & 130 & 2.44 & $1.80-3.30$ & $<.01$ & 2.15 & $1.55-2.97$ & $<.01$ \\
\hline IIIB & 39 & 3.91 & $2.57-5.94$ & $<.01$ & 3.22 & $2.05-5.06$ & $<.01$ \\
\hline
\end{tabular}

$C O P D$, Chronic obstructive pulmonary disease; $S C C$, squamous cell carcinoma; $A C$, adenocarcinoma; $L C C$, large cell carcinoma.

Our study is one of a few retrospective studies addressing prognostic relevance of blood transfusions in NSCLC patients. This analysis included a relatively large patient sample and, in contrast to other studies in NSCLC, also addressed the impact of autologous blood transfusion.

We demonstrated an adverse effect of allogeneic blood transfusion in univariate analysis but not in the multivariate model. There was also no independent effect of allogeneic transfusion when all patients with stage III tumors or patients who underwent pneumonectomy were excluded from analysis. Thus, allogeneic blood transfusion did not prove to be an independent negative predictor of survival when other prognostic variables were taken into account.

Neither in univariate nor in multivariate analysis did we find any significant survival differences between autologous versus allogeneic or between autologous versus nontransfused patients. The latter observation corresponds to the results of the only 2 studies addressing the impact of autol- ogous blood transfusion, ${ }^{16,17}$ both performed in colorectal cancer.

In retrospective analysis the impact of a given variable on survival may be difficult to assess due to other confounding covariates. Thus, it is important to include as many known prognostic factors as possible and to employ multivariate rather than univariate statistical models. Nevertheless, a selection bias may occur even if all attempts are taken to balance the distribution of all known prognostic factors.

It has been suggested that a randomized clinical trial with adequate power to detect a relatively minor survival difference might give a definite answer to this relevant clinical problem. ${ }^{19}$ However, such a study does not seem feasible for a number of reasons. A major intraoperative or postoperative blood loss requiring allogeneic blood transfusion cannot be determined before randomization. Furthermore, unnecessary exposure to allogeneic blood may not be acceptable due to ethical reasons. Another approach, although 
TABLE 3. Prognostic impact of allogeneic blood transfusion in NSCLC patients: data from the literature

\begin{tabular}{|c|c|c|c|c|}
\hline Author and reference & $\begin{array}{c}\text { Number of } \\
\text { patients }\end{array}$ & $\begin{array}{l}\text { Analyzed } \\
\text { outcome }\end{array}$ & Statistical analysis & Result \\
\hline Moores and colleagues ${ }^{11}$ & 330 & OS, RFS & $\begin{array}{l}\text { Stratified log-rank test; Cox proportional } \\
\text { hazard model }\end{array}$ & $\begin{array}{l}\text { Negative impact on } \\
\text { both OS and RFS }\end{array}$ \\
\hline Hyman and colleagues ${ }^{9}$ & 155 & OS & $\begin{array}{l}\text { Multiple-covariate adjusted log-rank test; } \\
\text { Cox proportional hazard model }\end{array}$ & Negative impact \\
\hline Little and colleagues ${ }^{10}$ & 117 & OS & $\begin{array}{l}\text { Parametric accelerated failure time } \\
\text { regression model }\end{array}$ & Negative impact \\
\hline Tartter and colleagues ${ }^{8}$ & 165 & OS & Cox proportional hazard model & Negative impact \\
\hline Keller and colleagues ${ }^{12}$ & 352 & RFS & $\begin{array}{l}\text { Stratified log-rank test; partial likelihood } \\
\text { ratio test }\end{array}$ & No impact \\
\hline Pastorino and colleagues ${ }^{13}$ & 283 & OS & Stratified log-rank test & No impact \\
\hline Present study & 493 & OS & Cox proportional hazard model & No impact \\
\hline
\end{tabular}

OS, Overall survival; $R F S$, relapse-free survival.

not free of some potential biases of retrospective studies, is an appropriately designed case-control study.

The blood transfusion rate accompanying pulmonary resection varies in particular series from $36 \%$ to $55 \% .^{8-13} \mathrm{In}$ our series the frequency of transfusions $(67 \%)$ was higher than in most studies including operable NSCLC. This outcome is due to several factors including mainly frequent preoperative blood donation, relatively high incidence of squamous cell carcinoma typically located centrally and necessitating more extensive resection, relatively high percentage of stage III disease, and routinely performed complete mediastinal lymph node dissection.

In conclusion, our study failed to support the hypothesis that blood transfusion, be it allogeneic or autologous, has a detectable detrimental effect on survival. However, we will continue to avoid blood transfusions in cancer patients whenever possible due to other potential risks carried by this procedure. In our opinion, the indications for transfusion of allogeneic or autologous blood should be limited to low hemoglobin or hematocrit levels, combined with the clinical symptoms of inadequate tissue oxygenation.

\section{References}

1. Opelz G, Sengar DP, Mickey MR, Terasaki PI. Effect of blood transfusion on subsequent kidney transplants. Transplant Proc. 1973; 5:253-9.

2. Burrows L, Tartter P. Effect of blood transfusion on colonic malignancy recurrence rate. Lancet. 1982;2:662.

3. Tartter PI. Blood transfusion and postoperative infections. Transfusion. 1989;25:456-9.

4. Triulzi DJ, Blumberg N. The association of transfusion with postoperative bacterial infection. Crit Rev Lab Sci. 1990;28:95-107.

5. Blumberg N, Triulzi DJ, Heal JM. Transfusion-induced immunomodu- lation and its clinical consequences. Trans Med Rev. 1990;4(Suppl 1):24-35.

6. Lappiere V, Auperin A, Tiberghien P. Transfusion-induced immunomodulation following cancer surgery: fact or fiction? J Natl Cancer Inst. 1998;90:573-80.

7. Landers DF, Hill GE, Wong KC, Fox IJ. Blood transfusion-induced immunomodulation. Anesth Analg. 1996;82:187-204.

8. Tartter PI, Burrows L, Kirschner P. Perioperative blood transfusion adversely affects prognosis after resection of stage I (subset N0) non-oat cell lung cancer. J Thorac Cardiovasc Surg. 1984;88:659-62.

9. Hyman NH, Foster NS, DeMeules JE, Constanza MC. Blood transfusions and survival after lung cancer resection. Am J Surg. 1985;149: 502-7.

10. Little AG, Huai-Shen ?? Wu, Ferguson MK, et al. Perioperative blood transfusion adversely affects prognosis of patients with stage I nonsmall cell lung cancer. Am J Surg. 1990;160:630-3.

11. Moores DWO, Piantadosi S, McKneally MF. Effect of perioperative blood transfusion on outcome in patients with surgically resected lung cancer. Ann Thorac Surg. 1989;47:346-51.

12. Keller SM, Groshen S, Martini N, Kaiser LR. Blood transfusion and lung cancer recurrence. Cancer. 1988;62:606-10.

13. Pastorino U, Valente M, Cataldo I, Lequaglie C, Ravasi G. Perioperative blood transfusion and prognosis of resected stage Ia lung cancer. Eur J Cancer Clin Oncol. 1986;22:1375-8.

14. Waymack JP, Robb E, Alexander JW. Effect of transfusion on immune function in a traumatized animal model: II. Effect on mortality rate following septic challenge. Arch Surg. 1987;122:935-9.

15. Waymack JP, Chance WT. Effect of blood transfusion on immune function: IV. Effect on tumor growth. J Surg Oncol. 1988;39:159-64.

16. Busch ORC, Hop WCJ, Hoynck van Papendrecht MAW, Marquet RI, Jeekel J. Blood transfusion and prognosis in colorectal cancer. N Engl J Med. 1993;328:1372-6.

17. Heiss MM, Mempel W, Delanoff C, et al. Blood transfusion-modulated tumor recurrence: first results of a randomized study of autologous versus allogeneic blood transfusion in colorectal cancer surgery. J Clin Oncol. 1994;12:1859-67.

18. McAllister FA, Clark HD, Wells PS, Laupacis A. Perioperative allogeneic blood transfusion does not cause adverse sequelae in patients with cancer: a meta-analysis of unconfounded studies. Br J Surg. 1998;85:171-8.

19. Piantadosi S. The adverse effect of blood transfusion in lung cancer. Chest. 1992;102:6-8. 